University of Nebraska - Lincoln

DigitalCommons@University of Nebraska - Lincoln

\title{
$4-2011$
}

\section{Magnetic entropy changes in nanogranular $\mathrm{Fe}_{\mathrm{Ni}} \mathrm{N}_{1} \mathrm{Cu}_{39}$}

\author{
Steven A. Michalski \\ University of Nebraska-Lincoln, smichalski2@unl.edu \\ Ralph A. Skomski \\ University of Nebraska-Lincoln, rskomski2@unl.edu \\ Tathagata Mukherjee \\ University of Nebraska-Lincoln, tatha.muk@gmail.com \\ Xingzhong Li \\ University of Nebraska-Lincoln, xli2@unl.edu \\ Christian Binek \\ University of Nebraska-Lincoln, cbinek@unl.edu \\ See next page for additional authors
}

Follow this and additional works at: https://digitalcommons.unl.edu/physicsbinek

Part of the Physics Commons

Michalski, Steven A.; Skomski, Ralph A.; Mukherjee, Tathagata; Li, Xingzhong; Binek, Christian; and Sellmyer, David J., "Magnetic entropy changes in nanogranular Fe:Ni61Cu39" (2011). Christian Binek Publications. 71.

https://digitalcommons.unl.edu/physicsbinek/71

This Article is brought to you for free and open access by the Research Papers in Physics and Astronomy at DigitalCommons@University of Nebraska - Lincoln. It has been accepted for inclusion in Christian Binek Publications by an authorized administrator of DigitalCommons@University of Nebraska - Lincoln. 


\section{Authors}

Steven A. Michalski, Ralph A. Skomski, Tathagata Mukherjee, Xingzhong Li, Christian Binek, and David J. Sellmyer 


\title{
Magnetic entropy changes in nanogranular Fe: $\mathrm{Ni}_{61} \mathrm{Cu}_{39}$
}

\author{
S. Michalski, ${ }^{\text {a) }}$ R. Skomski, T. Mukherjee, X.-Zh. Li, Ch. Binek, and D. J. Sellmyer \\ Department of Physics and Astronomy and Nebraska Center for Materials and Nanoscience, \\ University of Nebraska, Lincoln, Nebraska 68588, USA
}

(Presented 15 November 2010; received 24 September 2010; accepted 29 December 2010; published online 5 April 2011)

\begin{abstract}
Artificial environment-friendly Gd-free magnetic nanostructures for magnetic cooling are investigated by temperature-dependent magnetic measurements. We consider two-phase nanocomposites where nanoclusters $(\mathrm{Fe})$ are embedded in a $\mathrm{Ni}_{61} \mathrm{Cu}_{39}$ matrix. Several composite films are produced by cluster deposition. The average Fe cluster size depends on the deposition conditions and can be tuned by varying the deposition conditions. The quasiequilibrium Curie temperature of the Fe particles is high, but slightly lower than that of bulk Fe due to finite-size effects. Our experiments have focused on ensembles of $7.7 \mathrm{~nm}$ Fe clusters in a matrix with a composition close to $\mathrm{Ni}_{61} \mathrm{Cu}_{39}$, which has a $T_{C}$ of $180 \mathrm{~K}$. The materials are magnetically soft, with coercivities of order 16 Oe even at relatively low temperature of $100 \mathrm{~K}$. The entropy changes are modest, $-\Delta S=0.05 \mathrm{~J} / \mathrm{kg} \mathrm{K}$ in a field change of $1 \mathrm{~T}$ and $0.30 \mathrm{~J} / \mathrm{kg} \mathrm{K}$ in a field change of $7 \mathrm{~T}$ at a temperature of $180 \mathrm{~K}$, which should improve if the cluster size is reduced. (C) 2011 American Institute of Physics. [doi:10.1063/1.3562254]
\end{abstract}

\section{INTRODUCTION}

Room-temperature magnetic refrigeration based on the magnetocaloric effect has attracted increasing interest in recent years. ${ }^{1-4}$ This is because magnetic refrigeration technology is intrinsically environment-friendly and potentially more energy efficient compared to current compression and evaporation technology. ${ }^{1}$ Current technology uses ozonedepleting chlorofluorocarbons, which could be eliminated by switching to magnetic refrigeration. Moreover, magnetic cooling can be more efficient than current gas-compression refrigerators, namely $60 \%$ for Gd-based systems, compared to $40 \%$ for gas compression. ${ }^{2}$ Developing an efficient magnetic refrigerator requires a material with a large magnetic entropy change at low magnetic fields and operating temperatures near room temperature. A recent research trend is a shift from simple bulk materials toward artificially produced complex magnetic structures, such as ternary compounds ${ }^{1,3}$ ultrathin films, ${ }^{5}$ and granular nanostructures. ${ }^{4,6}$ The idea is to use the effects of structuring to improve the performance of the materials by maximizing the entropy change in lower magnetic fields, suppressing hysteresis losses, and tuning the operation temperature to a desired range.

Traditionally, magnetic phase transitions are used to increase the magnetic entropy change and the operation temperature as at the transition the interatomic exchange $J_{\mathrm{ex}}$ enhances the effect of the applied magnetic field. ${ }^{1,3} \mathrm{We}$ also plan to use phase-transition effects but our main thrust goes in a different direction, namely to effectively enhance the quantum number $J$, or the total spin $S_{\text {spin }} \sim J$, to maximize the entropy change. This can be done by embedding ferromagnetic nanoparticles or clusters of $\mathrm{N}$ atoms with large "macrospins" $J \sim N$ in an interacting matrix. ${ }^{6,7}$ The entropy $S$ increases logarithmically with $N$, but for large clusters this

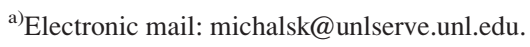

increase is overcompensated by a large heat capacity $C \sim N$, therefore we need to use small clusters. Also the nanostructuring helps reduce the magnetic field necessary for saturation $H \sim 1 / N{ }^{7}$

This paper focuses on two-phase nanocomposites where $\mathrm{Fe}$ nanoclusters are embedded in a disordered-alloy matrix of $\mathrm{Ni}-\mathrm{Cu}$. The quasiequilibrium Curie temperature of the $\mathrm{Fe}$ particles is high, but slightly lower than that of bulk Fe, due to finite-size effects. $\mathrm{Ni}-\mathrm{Cu}$ was chosen for the matrix because it is already available and because its Curie temperature can be tuned by varying the copper concentration. Bulk $\mathrm{Ni}_{70} \mathrm{Cu}_{30}$ has a Curie temperature of $T_{C}=300 \mathrm{~K}$, which decreases with decreasing $\mathrm{Ni}$ concentration at a rate of about $11 \mathrm{~K} / \mathrm{at} . \% \mathrm{Ni}^{8}{ }^{8}$ Our current work focuses on ensembles of Fe clusters having an average cluster size of $7.7 \mathrm{~nm}$ in a matrix with compositions close to $\mathrm{Ni}_{61} \mathrm{Cu}_{39}$.

\section{EXPERIMENTAL METHODS}

The Fe clusters were fabricated in a cluster-deposition system. ${ }^{9}$ The system produces clusters by combining a dc magnetron sputtering gun using argon and helium as process gases, and the gas-aggregation chamber was held at a temperature of $-140^{\circ} \mathrm{C}$. The cluster size can be controlled by varying sputtering power, Ar flow rate, He flow rate, and gas-aggregation chamber length. The system also contains two sputtering guns for different matrix materials. All samples were deposited onto to $\mathrm{Si}$ (100) substrates. To compare the effects of embedding the clusters, three types of samples were produced. The first sample is a $\mathrm{Ni}_{61} \mathrm{Cu}_{39} 56.7$-nm-thick matrix without $\mathrm{Fe}$ clusters, the second type are a series of $\mathrm{Ni}_{61} \mathrm{Cu}_{39}$ with $\mathrm{Fe}$ clusters embedded. The processes of making the cluster-embedded samples are similar to the deposition of the multilayers. First, the matrix material is deposited, then clusters are deposited for a time $t$ and the process is repeated until the desired thickness is reached. 
The samples in this series have the structure $\left(\left[\mathrm{Ni}_{61} \mathrm{Cu}_{39} 2.08\right.\right.$ $\left.\mathrm{nm} / \mathrm{Fe}(t)]_{15} / \mathrm{Ni}_{61} \mathrm{Cu}_{39} 3 \mathrm{~nm}\right)$. We have used times $t$ of 20, 30, and $40 \mathrm{~s}$, which correspond to Fe volume fractions of $21 \%$, $28 \%$, and $34 \%$, respectively. The samples had thicknesses of $43.5-53.3 \mathrm{~nm}$. The third type of sample was the Fe clusters embedded into a nonmagnetic $\mathrm{SiO}_{2}$ matrix with a structure of ([ $\mathrm{SiO}_{2} 2.05 \mathrm{~nm} / \mathrm{Fe}$ cluster $\left.\left.20 \mathrm{~s}\right]_{10} / \mathrm{SiO}_{2} 3.4 \mathrm{~nm}\right)$, yielding a $20 \%$ volume fraction of $\mathrm{Fe}$ and a thickness of $30 \mathrm{~nm}$. The cluster size was measured with a transmission electron microscope (TEM), and the $\mathrm{Ni}-\mathrm{Cu}$ atomic percentages were determined by an x-ray energy-dispersive spectrometer in a scanning electron microscope on a 200 -nm-thick film. We measured several spots on the film and obtained a composition of $\mathrm{Ni}_{61} \mathrm{Cu}_{39}$ with an error of $1 \%$. The magnetic properties were measured using a superconducting interference device with a maximum magnetic field of $7 \mathrm{~T}$ and a maximum temperature of $400 \mathrm{~K}$.

\section{RESULTS AND DISCUSSION}

Figure 1 shows a TEM picture of the Fe clusters after a $15 \mathrm{~s}$ deposition onto a TEM $\mathrm{Cu}$ grid with a $2.3 \mathrm{~nm}$ overcoat of $\mathrm{SiO}_{2}$. The size distribution of the particles and a Gaussian fit are shown in the inset; the average diameter is $7.7 \mathrm{~nm}$ and the standard deviation $\sigma / D$ is 0.12 . As deposited the Fe clusters are in a bcc structure. Zero-field cooled (ZFC) and field cooled (FC) data, as well as hysteresis loops on $\left(\left[\mathrm{SiO}_{2} 2.05\right.\right.$ $\mathrm{nm} / \mathrm{Fe}$ cluster $20 \mathrm{~s}]_{10} / \mathrm{SiO}_{2} 3.4 \mathrm{~nm}$ ), show that the Fe clusters are superparamagnetic with a blocking temperature of about $200 \mathrm{~K}$. Below $200 \mathrm{~K}$, they are magnetically soft with coercivity under 50 Oe at $100 \mathrm{~K}$.

Here we present and discuss the magnetic data on the matrix material 56.7-nm-thick $\mathrm{Ni}_{61} \mathrm{Cu}_{39}$. The Curie temperature, as estimated by inspection from the $\mathrm{ZFC}$ and $\mathrm{FC}$ curves shown in the inset of Fig. 2(a), is about $180 \mathrm{~K}$. The $M(H)$ isotherms in fields $0 \geq \mu_{0} H \geq 7 \mathrm{~T}$ were measured for $T=120-220 \mathrm{~K}$ in steps of $5 \mathrm{~K}$. All isotherms have been initialized by zero-field cooling from $380 \mathrm{~K}$. Figure 2(a) shows the sampling of the isotherms. As the phase change is second order, the change of isothermal entropy $\Delta S$ was calculated using isotherm data and the Maxwell relation:

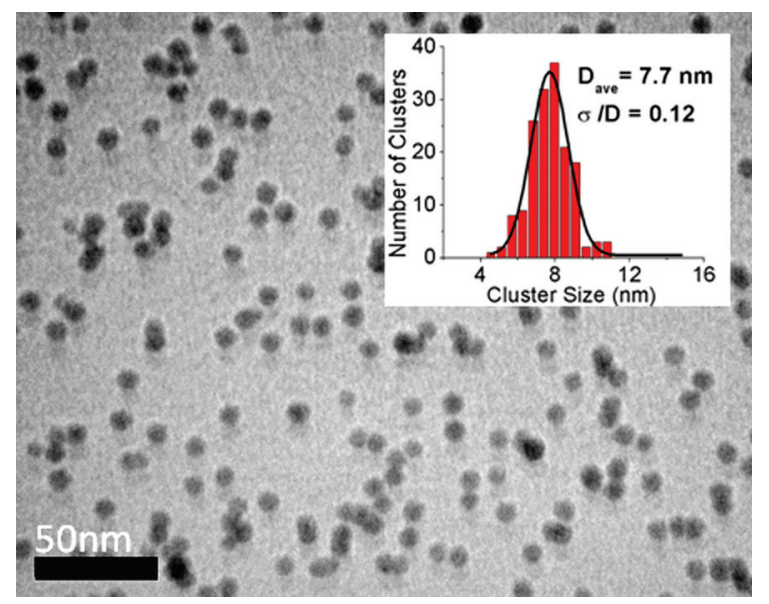

FIG. 1. (Color online) Fe clusters: TEM micrograph. The inset shows the size distribution and Gaussian fit of the size distribution.
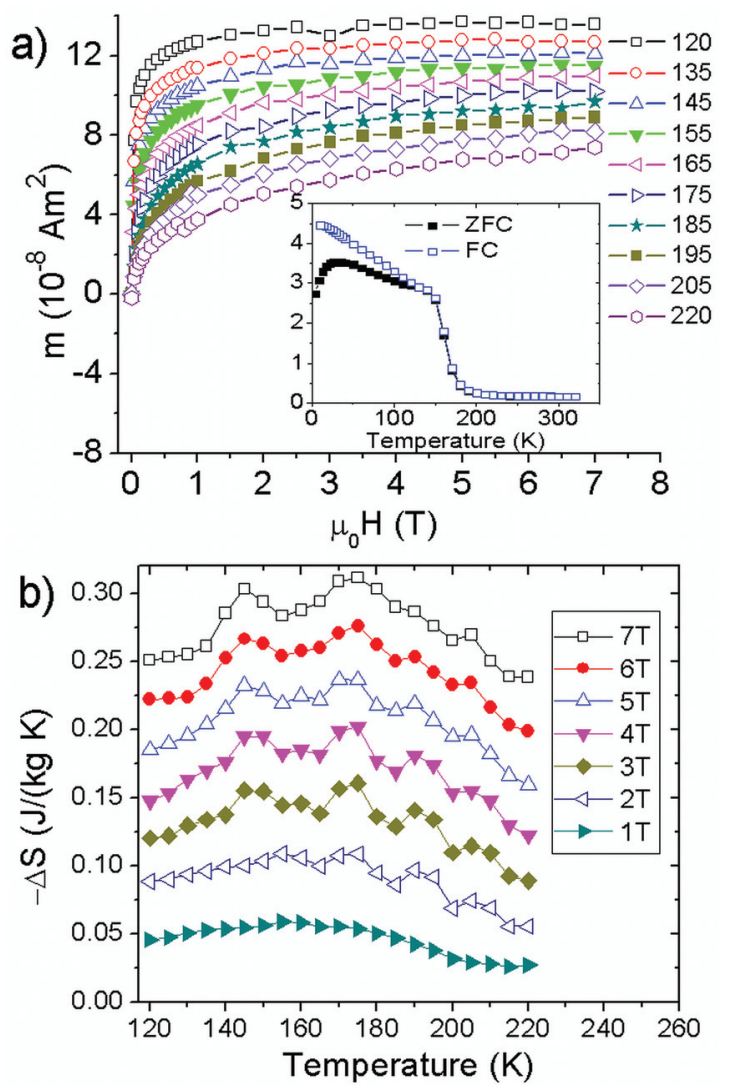

FIG. 2. (Color online) Magnetic and entropic properties of the sample $\mathrm{Ni}_{61} \mathrm{Cu}_{39} 56.7 \mathrm{~nm}$ : (a) Isotherms at various temperatures (the inset shows ZFC-FC curves in for in-plane applied field of 100 Oe indicating a phase transition around $180 \mathrm{~K})$. (b) Entropy change $-\Delta \mathrm{S}$ as a function of temperature, as calculated from the Maxwell relation for various $\mu_{0} \Delta H$.

$$
\Delta S=\mu_{0} \int_{0}^{\mu_{0} H}\left(\frac{\partial m}{\partial T}\right)_{H} d H
$$

where $m$ is the magnetic moment of the sample. Figure 2(b) show the $-\Delta S$ as function of temperature for the $56.7 \mathrm{~nm}$ $\mathrm{Ni}_{61} \mathrm{Cu}_{39}$ sample in magnetic field changes up to $7 \mathrm{~T}$. The mass of the active magnetic layer was estimated using the volume deposited and assuming a density of $8.92 \mathrm{~g} / \mathrm{cm}^{3}$ The $\mathrm{Ni}-\mathrm{Cu}$ matrix produces a small entropy change, $-\Delta \mathrm{S} \sim 0.3$ $(\mathrm{J} /(\mathrm{kg} \mathrm{K})$, in a field change of $7 \mathrm{~T}$, with a maximum near the Curie temperature of the $\mathrm{Ni}-\mathrm{Cu}$ alloy.

All three of the $\left(\left[\mathrm{Ni}_{61} \mathrm{Cu}_{39} 2.08 \mathrm{~nm} / \mathrm{Fe}(t) \mathrm{s}\right]_{15} / \mathrm{Ni}_{61} \mathrm{Cu}_{39}\right.$ $3 \mathrm{~nm}$ ) have similar magnetic properties. They are magnetically soft with coercivities of less than 16 Oe at both 100 and $300 \mathrm{~K}$. Figure 3(a) shows a typical set of isotherms, measured for the sample $\left(\left[\mathrm{Ni}_{61} \mathrm{Cu}_{39} 2.08 \mathrm{~nm} / \mathrm{Fe}\right.\right.$ clusters $t=40$ $\mathrm{s}]_{15} / \mathrm{Ni}_{61} \mathrm{Cu}_{39} 3 \mathrm{~nm}$ ). The inset shows ZFC data with in-plane applied fields of 50 and 200 Oe; no sharp transitions are observed. Based on the ZFC data, the isotherms were measured over a relatively large temperature range of 50-200 K, in steps of $10 \mathrm{~K}$. To initialize the isotherms, they were zerofield cooled from $380 \mathrm{~K}$.

For consistency, the isothermal entropy change, Fig. 3(b), was calculated from the isotherms using the Maxwell relation, Eq. (1). The entropy changes is $-\Delta S=0.09 \mathrm{~J} /(\mathrm{kg} \mathrm{K})$ for $\mu_{0} \Delta H=1 \mathrm{~T}$ and reaches a maximum of $0.31 \mathrm{~J} /(\mathrm{kg} \mathrm{K})$ for $\mu_{0} \Delta H=7 \mathrm{~T}$ at $180 \mathrm{~K}$. The main reason for this modest 

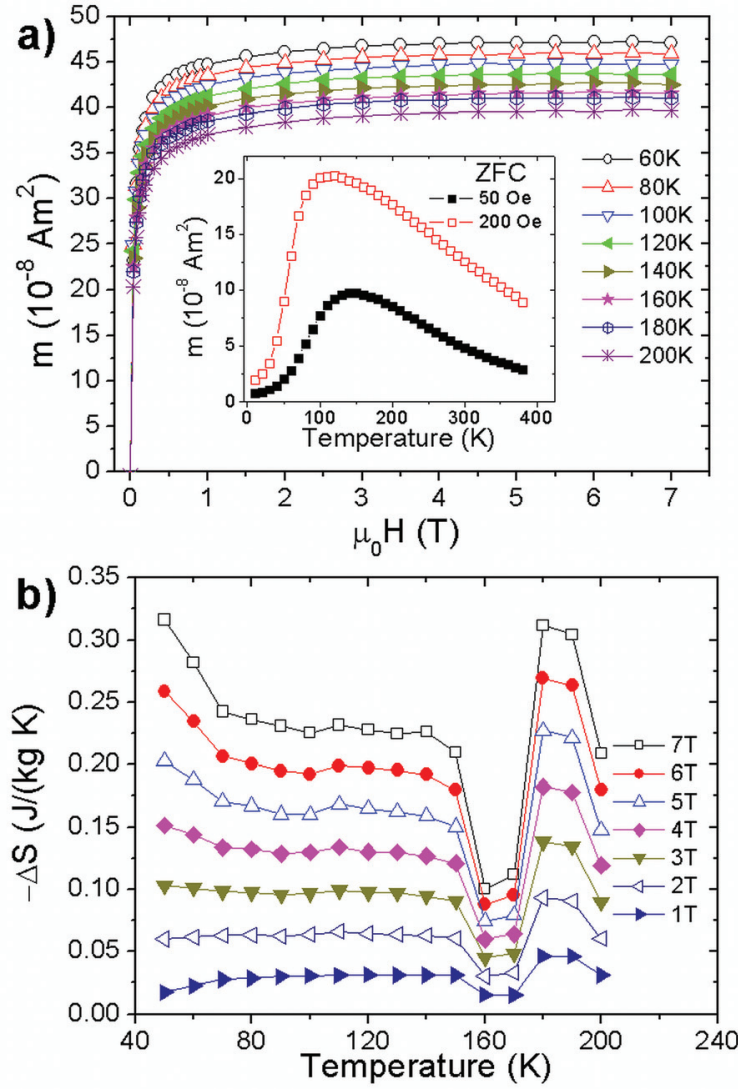

FIG. 3. (Color online) Magnetic and entropic properties of the sample ( $\left[\mathrm{Ni}_{61} \mathrm{Cu}_{39} 2.08 \mathrm{~nm} / \mathrm{Fe} \text { clusters } t=40 \mathrm{~s}\right]_{15} / \mathrm{Ni}_{61} \mathrm{Cu}_{39} 3 \mathrm{~nm}$ ). (a) Isotherms at various temperatures (the inset shows ZFC curves for in-plane applied fields of 50 and $200 \mathrm{Oe}$ ). (b) Entropy change $-\Delta \mathrm{S}$ as a function of temperature, as calculated from the Maxwell relation.

entropy change is that the Fe cluster-embedded samples do not have a sharp drop in the magnetization associated with a phase transition. The phase transition of the matrix disappears due to the exchange-coupling of the Fe cluster with a high $\mathrm{Cu}$ rie temperature to the low Curie temperature $\mathrm{Ni}-\mathrm{Cu}$ matrix producing a net Curie temperature between the two phases. ${ }^{10,11}$ The effect of the exchange-coupling on the entropy change is rather weak, and strongly decreases with increasing Curie-temperature difference between matrix and embedded clusters. ${ }^{7}$ Even though the entropy change is small, the entropy curves change from the $\mathrm{Ni}-\mathrm{Cu}$ matrix showing a pronounced minimum at around $160 \mathrm{~K}$ and a maximum at around $180 \mathrm{~K}$, which must be due to the interaction with the Fe clusters. As, model calculations show that for a fixed volume fraction of Fe, the entropy change decreases with increasing radius of the clusters using smaller clusters should increase the entropy change. .,8 $^{2}$

\section{CONCLUSION}

In conclusion, we have presented preliminary experiments on nanogranular $\mathrm{Fe}: \mathrm{Ni}_{61} \mathrm{Cu}_{39}$ to investigate the effect of nanostructuring on the entropy change in a magnetic field. In the present system, the entropy change is only modest, but we do see promising evidence of a peak forming in the change of entropy due to the coupling between the nanoclusters and the matrix. Further experimental research is underway to reduce the particle size and to fully exploit the potential of magnetic nanostructures for magnetic cooling.

\section{ACKNOWLEDGMENTS}

This work is supported by NSF-MRSEC Grant No. DMR-0820521, NRI, and NCMN. The authors are grateful to Dr. Balamurugan Balasubramanian and Dr. Parashu Ram Kharel for discussing various details of this work.

${ }^{1}$ E. Brück, O. Tegus, D. T. C. Thanh, and K. H. J. Buschow, J. Magn. Magn. Mater. 310, 2793 (2007)

${ }^{2}$ C. Zimm, A. Jastrab, A. Sternberg, V. Pecharsky, and K. Geschneidner, Jr., Adv. Cryog. Eng. 43, 1759 (1998).

${ }^{3}$ K. A. Gschneidner, Jr., V. K. Pecharsky, and A. O. Tsokol, Rep. Prog. Phys. 68, 1479 (2005)

${ }^{4}$ R. D. McMichael, R. D. Shull, L. J. Swartzendruber, and L. H. Bennett, J. Magn. Magn. Mater. 111, 29 (1992).

${ }^{5}$ T. Mukherjee, S. Sahoo, R. Skomski, D. J. Sellmyer, and Ch. Binek, Phys. Rev. B 79, 144406 (2009).

${ }^{6}$ R. Skomski, Ch. Binek, T. Mukherjee, S. Sahoo, and D. J. Sellmyer, J. Appl. Phys. 103, 07B329 (2008).

${ }^{7}$ R. Skomski, Ch. Binek, S. Michalski, T. Mukherjee, A. Enders, and D. J. Sellmyer, J. Appl. Phys. 107, 09A922 (2010).

${ }^{8}$ S. A. Ahern, M. J. C. Martin, and W. Sucksmith, Proc. R. Soc. London, Ser. A 248, 145 (1958).

${ }^{9}$ Y. F. Xu, M. L. Yan, and D. J. Sellmyer, in Advanced Magnetic Nanostructures, edited by D. J. Sellmyer and R. Skomski (Springer, New York, 2006), Chap. 8, p. 207.

${ }^{10}$ R. Skomski, Simple Models of Magnetism (University Press, Oxford, 2008).

${ }^{11}$ R. Skomski and D. J. Sellmyer, J. Appl. Phys. 87, 4756 (2000). 